2020.2 . Ano XXXVII . Número 40

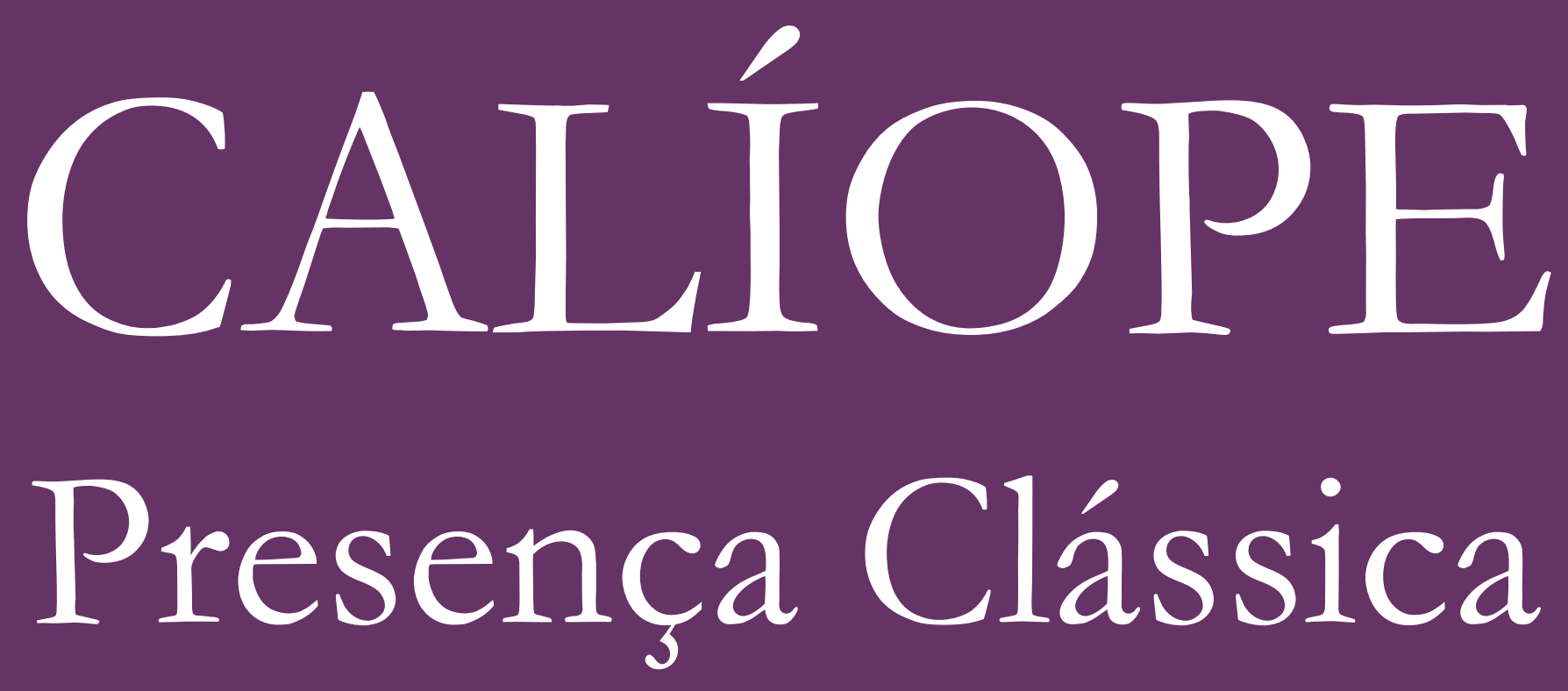

separata 5

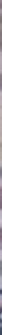

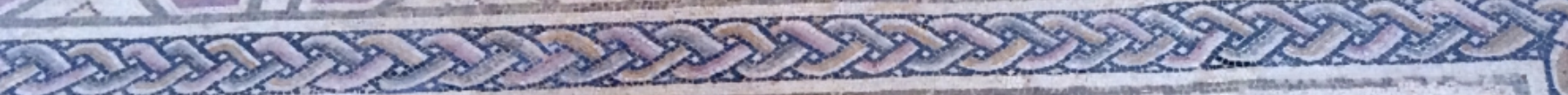

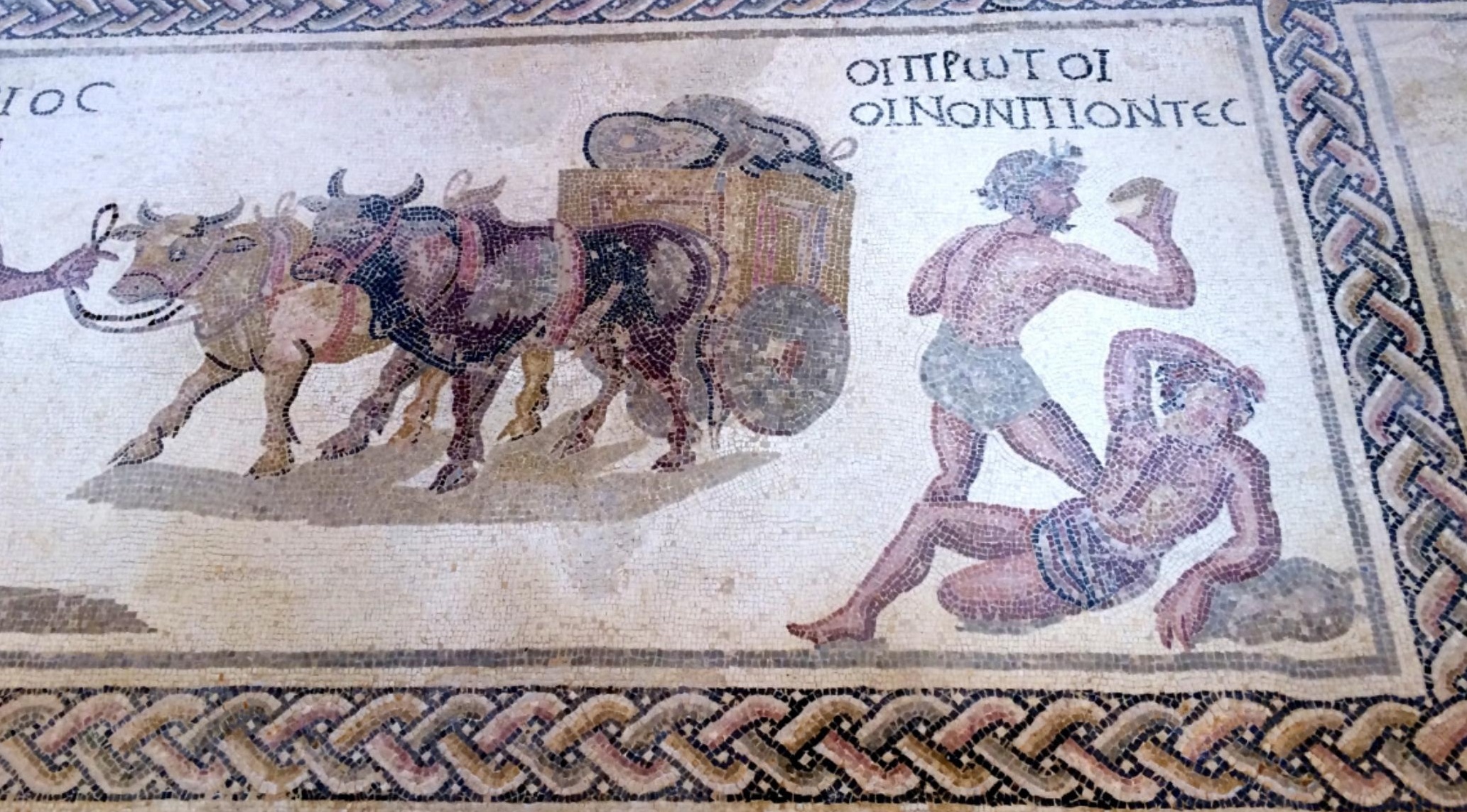


2020.2 . Ano XXXVII . Número 40

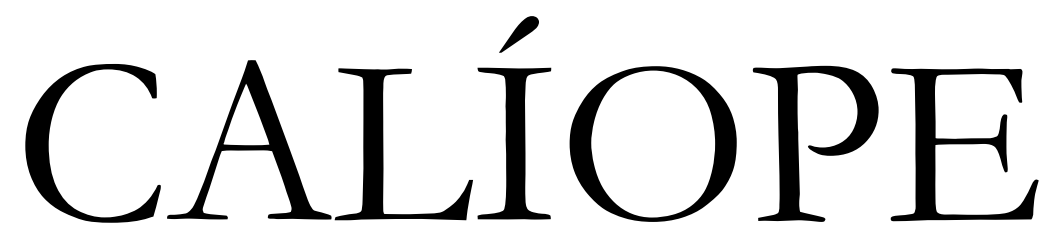

Presença Clássica ISSN 2447-875X

separata 5

Programa de Pós-Graduação em Letras Clássicas

Departamento de Letras Clássicas da UFRJ 
Universidade Federal do Rio de Janeiro

REITOR Denise Pires de Carvalho

Centro de Letras e Artes

DECANA Cristina Grafanassi Tranjan

Faculdade de Letras

DIRETORA Sonia Cristina Reis

Programa de Pós-Graduação em Letras Clássicas

COORDENADOR Rainer Guggenberger

VICE-COORDENADORA Ricardo de Souza Nogueira

Departamento de Letras Clássicas

CHEFE Fábio Frohwein de Salles Moniz

SUBCHEFE Eduardo Murtinho Braga Boechat

Organizadores

Fábio Frohwein de Salles Moniz

Rainer Guggenberger

Conselho Editoria

Alice da Silva Cunha

Ana Thereza Basilio Vieira

Anderson de Araujo Martins Esteves

Arlete José Mota Auto Lyra Teixeira

Ricardo de Souza Nogueira Tania Martins Santos

Conselho Consultivo

Alfred Dunshirn (Universität Wien)

David Konstan (New York University)

Edith Hall (King's College London)

Frederico Lourenço (Universidade de Coimbra)

Gabriele Cornelli (UnB)

Gian Biagio Conte (Scuola Normale Superiore di Pisa)

Isabella Tardin (Unicamp)

Jacyntho Lins Brandão (UFMG)

Jean-Michel Carrié (EHESS)

Maria de Fátima Sousa e Silva (Universidade de Coimbra)

Martin Dinter (King's College London)

Victor Hugo Méndez Aguirre (Universidad Nacional Autónoma de México)

Violaine Sebillote-Cuchet (Université Paris 1)

Zélia de Almeida Cardoso (USP)

Capa

Fábio Frohwein de Salles Moniz

Editoração

Fábio Frohwein de Salles Moniz

Revisão de texto

Rainer Guggenberget

Revisão técnica

Fábio Frohwein de Salles Moniz

Programa de Pós-Graduação em Letras Clássicas | Faculdade de Letras - UFR

Av. Horácio Macedo, 2151 - sala F-327 - Ilha do Fundão 21941-917 - Rio de Janeiro - RJ www.letras.ufrj.br/pgclassicas - pgclassicas@letras.ufrj.br 


\section{Percepciones político-culturales encontradas: griegos, romanos y philanthropia en las Historias de Polibio (IX.42.5-8) ${ }^{1}$ \\ Álvaro M. Moreno Leoni}

\section{RESUMEN}

Se ensaya aquí una interpretación de un pasaje fragmentario de las Historias de Polibio (IX.42.5-8), en el cual se narraba el episodio final de la toma de Egina durante la Primera Guerra Macedónica (210 a.C.), se ensaya aquí. El encuentro entre las perspectivas griegas y romanas sobre la noción de philanthropía se acentúa a fin de mostrar su importancia en el contexto de la lección pensada por Polibio sobre ejercicio moderado del poder.

PALABRAS CLAVES

Polibio; philanthropia; historiografía griega; didáctica.

SUBMISSÃO 24.7.2020 | APROVAÇÃO 14.8.2020 | PUBLICAÇÃO 21.4.2021

DOI https://doi.org/10.17074/cpc.v1i39.36741 


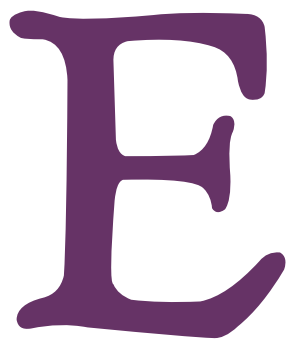

1 INTRODUCCIÓN

1 principal objetivo de Polibio era explicar la sorprendente expansión de Roma entre los siglos III-II a.C. Aunque no formuló una teoría coherente sobre el imperialismo, ${ }^{2}$ entendió que la comprensión de las circunstancias históricas concretas de la conquista ofrecía herramientas para los políticos contemporáneos que leyeran su obra. ${ }^{3}$ Ello quedaba claro desde el comienzo de las Historias con la pregunta planteada en el primer proemio: "¿Qué hombre será tan necio o negligente que no quiera conocer cómo y mediante qué tipo de constitución casi todo el mundo habitado, dominado en cincuenta y tres años no completos, cayó bajo un único imperio, el de los romanos?". ${ }^{4}$ Conocer eso era muy importante para poder apreciar el fenómeno desde la perspectiva de la experiencia presente. Sin embargo, con eso no bastaba, por lo que Polibio dedicó un segundo proemio para justificar una ampliación de su narración para poder cubrir con la misma los siguientes veinte años, con la incorporación adicional de otros diez libros. Así, los lectores serían capaces de juzgar, desde el presente, $a$ posteriori, "si su gobierno (i.e. de Roma) ha sido digno, bien de elogio y emulación, bien de vituperio". 5

Los conquistadores romanos fueron cuidadosamente construidos en la obra desde el libro I como un pueblo entregado a una permanente ambición y expansión territorial, que los condujo finalmente a alcanzar el dominio universal. ${ }^{6}$ Sin embargo, su indagación sobre el imperialismo romano no fue más allá de una indagación de sus bases constitucionales, en el libro VI, y de algunos de los aspectos morales implicados en la justicia o conveniencia del dominio ejercido sobre otros pueblos. Su reflexión tuvo un origen práctico, relacionado con su experiencia como hombre político de un Estado griego mediano, la Confederación aquea, que estaba muy preocupado y sensibilizado por el problema de la relación entre poderes hegemónicos y 
pequeños y medianos Estados, que, por aquel entonces, desesperadamente buscaban preservar sus márgenes de autonomía. Así, una de las preocupaciones fundamentales del historiador fue proporcionar opciones a la élite política griega que la orientaran a preservar honorable y eficazmente sus márgenes de decisión en las nuevas circunstancias históricas. ${ }^{7}$

No hace falta aclararlo. Polibio no fue un observador neutral. Su vida quedó inevitablemente atada a la expansión romana por el Mediterráneo oriental, momento en el que fue conducido como detenido político a Roma tras la Tercera Guerra Macedónica. Sin embargo, evitó sistemáticamente en sus Historias explicitar su postura personal sobre la justicia del dominio impuesto en aquellas circunstancias. El intento por descubrir la misma alimentó el debate historiográfico desde el siglo XIX, al menos desde la publicación de Polybe ou la Grèce conquise par les romains (1858) de Numa Fustel del Coulanges o Die Geschichten des Aetolischen Landes, Volkes und Bundes (1844) de Franz Brandstäter. ${ }^{8}$ En los últimos años, la historiografía parece haber arribado a cierto consenso: lejos de las posturas extremas, la posición de Polibio con respecto a Roma debe buscarse a mitad de camino entre una aceptación resignada y una solapada hostilidad. Como ha señalado Donald Baronowski, si bien en su texto no se advierte una impugnación abierta del imperialismo romano, tampoco puede obviarse las expresiones de reserva e independencia mental frente al fenómeno.?

Por lo tanto, parece importante apuntar a la permanencia de una reserva mental como actitud general. En efecto, en las últimas décadas, la discusión historiográfica ha virado hacia la preocupación por el grado de distanciamiento cultural entre historiador y objeto de estudio. ${ }^{10}$ Algunos autores, en ese sentido, han comenzado a prestar debida atención al hecho de que Polibio no parece haberse desligado por completo de su mirada extranjera, casi etnográfica, con respecto a los romanos, por lo que, cada vez con mayor insistencia, la clásica tesis de una identificación absoluta con los conquistadores, resultado de una "crisis" personal, o una "romanización" cultural del historiador, es dejada de lado. ${ }^{11}$ Por el 
contrario, Roma se percibe en las Historias como un objeto de estudio construido como tal, ${ }^{12}$ producto de una frontera cultural con los griegos, siempre permeable en la práctica, pero permanentemente separada en el imaginario. ${ }^{13}$

En consonancia, en el presente, el debate historiográfico busca restituir al historiador a su contexto cultural helenístico. En ese ámbito relacional complejo, las interacciones entre griegos y romanos se convirtieron en un espacio importante para la reflexión, sobre todo, cuando se narró las vicisitudes históricas del contacto inicial particularmente violento durante la Primera Guerra Macedónica (214-205 a.C.). ${ }^{14}$ En una primera etapa de la expansión romana hacia el Egeo, el contacto griego se redujo al trato personal con los comandantes individuales romanos destacados en el área. Al respecto, Baronowski ha reconocido que, para Polibio, la política romana frente al mundo griego tuvo una cierta coherencia hasta el 168 a.C., que se fundó generalmente en la moderación. ${ }^{15}$

Sin embargo, ello no siempre ocurrió de esa manera, o, al menos, no siempre se representó igual. La opinión de Baronowski, en efecto, no toma en consideración la campaña en Grecia de P. Sulpicio Galba durante la Primera Guerra Macedónica, que constituye el tema principal de este artículo. La fuente que nos informa sobre la misma es apenas un pasaje fragmentario del libro IX, en el que se recoge la noticia de la conquista de Egina, ciudad miembro de la Confederación aquea por aquel entonces. En nuestra opinión, Polibio acentúa allí una oposición entre percepciones político-culturales sobre la philanthropía (generosidad, humanidad) por parte de los actores implicados, romanos y griegos. El análisis puede aportar elementos interesantes para comprender el marco político-intelectual helenístico que daba sentido a la narración de la expansión romana, sin dejar de lado la reserva intelectual del historiador que se manifestaba en una distancia cultural frente a los invasores. Esta inquietud, por lo demás, está en sintonía con las preocupaciones historiográficas contemporáneas expuestas más arriba.

Baronowski ha reconstruido las líneas generales de una rica tradición intelectual helenística sobre la noción de imperio, que 
incluye tanto a historiadores como a filósofos antiguos, y ha llegado a la conclusión de que, salvo algunas excepciones, estos autores veían al imperialismo como una tendencia natural. ${ }^{16}$ Hay allí una notable continuidad en relación con la reflexión política clásica, según la cual, la libertad no se reducía a la preservación de la propia autonomía, sino que implicaba potencialmente la posibilidad de mandar a otros. El famoso carácter de hegemonikoi kaì phileleútheroi, "hegemónicos y amantes de la libertad", que Polibio atribuye a los peloponesios en el libro $\mathrm{v}$, constituye un resabio de esta concepción griega doble de la libertad. ${ }^{17}$ Tampoco se cuestiona el dominio sobre otros, como se advierte, por ejemplo, cuando el historiador menciona el fracaso de espartanos y tebanos en obtener una hegemonía duradera sobre Grecia (tèn tôn Hellénon hegemonian), lo considera potencialmente como el logro más hermoso al que se puede aspirar. ${ }^{18}$

En los últimos tiempos se ha puesto el acento en el hecho de que las prácticas y las reflexiones políticas helenísticas tuvieron su origen en las fluidas interacciones entre reyes y póleis. Ello se ha observado en la zona de contacto en la zona micro asiática, donde, desde el siglo IV a.C., se experimentó un solapamiento entre las ambiciones territoriales de las grandes monarquías (los seléucidas) y los intentos de las ciudades de preservar márgenes de autonomía. Se ha llamado la atención no solo sobre el paralelo entre el lenguaje de las cartas reales y el de los decretos cívicos con el de Polibio, sino también sobre la lógica política común. ${ }^{19}$ Para ello, John Ma ha hecho un aporte fundamental al conocimiento de las interacciones discursivas y performativas en el abordaje de las relaciones epistolares entre Antíoco III y las póleis de Asia Menor occidental. ${ }^{20}$ El lenguaje evergético, que permitía traducir relaciones de poder asimétricas a términos moralmente aceptables para los actores involucrados, permea a estas cartas. ${ }^{21}$ Los reyes podían reducir así la violencia implícita de las órdenes, reproduciendo en la práctica una lógica imperial de interacción, al tiempo que las póleis tenían la oportunidad de obligar moralmente, apelando al propio discurso real evergético para ampliar el espacio práctico de negociación. 
En el plano de la comunidad panhelénica, el lenguaje del evergetismo se tradujo en un uso más frecuente, por ejemplo, de fórmulas honoríficas como la de koinòs euergétes tôn Hellénon ("benefactor común de los griegos"). Al respecto, Teos la utilizó para honrar -y obligar moralmente- a Antíoco III (204/3 a.C.), así como también la Liga de los Jonios con Eumenes II (167 a.C.). ${ }^{22}$ Las póleis incorporaron a los romanos rápidamente al terreno discursivo de este lenguaje político. La fórmula se observa ya, por ejemplo, en un decreto de proxenía que Delfos, o quizá la Anfictionía misma, votó en honor del historiador Aristodeo de Trecén (157 a.C.), quien había recitado "encomios a los romanos, los benefactores comunes de los griegos (toùs koinoùs tôn Helládon [eu]ergétas)". ${ }^{23}$ Existen más ejemplos entre los años 182 y 62 a.C. ${ }^{24}$

Este lenguaje político coincide con lo que Polibio imaginó como una relación todavía posible entre Roma y el mundo griego del siglo II a.C. Al respecto, John Thornton ha argumentado recientemente que el principal propósito del historiador era enviar un mensaje "diplomático" a la élite política romana sobre cómo llevar adelante de forma moderada un imperio. ${ }^{25}$ Algo parecido había sido planteado en el pasado por Jacqueline de Romilly, JeanLouis Ferrary, Andrew Erskine, o Ryan Balot, quienes habían puesto el énfasis en los objetivos didácticos. En líneas generales, todos reconocían que la provisión de ejemplos históricos de comportamiento moderado estaba orientada a suavizar la experiencia griega del dominio romano. ${ }^{26}$ Contra Arnaldo Momigliano, que imaginó a un Polibio preocupado exclusivamente por explicar a griegos y romanos las razones por las que estos últimos estaban destinados a la victoria, los estudios más recientes muestran el involucramiento activo del historiador aqueo en lograr que la derrota resultara menos pesada para la élite griega. ${ }^{27}$

A partir de la propuesta teórica de James Scott, sobre la dinámica entre "discursos públicos" y "discursos ocultos" como arma de resistencia, Thornton ha redimensionado la cuestión al instalarla en el terreno diplomático, que tiene mucho en común la apelación a un lenguaje político común, tal como lo entiende Elías Palti. ${ }^{28}$ Así, el supuesto prorromanismo y la pretendida adopción 
del punto de vista imperial, que supone la tesis de una "conversión", se entenderían en cambio como "un intento, usando medios diplomáticos, de convencer a los representantes del poder hegemónico de poner en práctica las declaraciones grandilocuentes de principio contenidas en sus discursos y documentos oficiales". ${ }^{29}$ Allí, estaría el punto de toque con el aporte de John Ma y las relaciones entre Antíoco III y las ciudades de Asia Menor: el discurso tiene cierto poder performativo. La propuesta implicaría una adhesión calculada al discurso público romano con el objetivo de convencer a los nuevos dominadores de mantener la imagen pública que habían sistemáticamente diseminado desde fines de la Segunda Guerra Macedónica. ${ }^{30}$ De esa forma habría procedido, por ejemplo, Calcis de Eubea. La ciudad había abierto sus puertas a Antíoco III al comienzo de su guerra contra Roma y, tras la batalla de Termópilas (191 a.C.), T. Quincio Flaminino intercedió en su favor ante M. Acilio Glabrión. ${ }^{31}$ Agradecida, decretó honrar a su "salvador" con un festival anual, que incluía el canto de un himno en honor a Zeus, Dea Roma, Flaminino Sôter y la Pístis romana. ${ }^{32}$ A esto mismo apuntaba Filopemén, político aqueo, quien en su célebre debate con Aristeno instaba a intentar siempre primero persuadir a los romanos de mantenerse dentro de los límites de su propio discurso público, exaltando, al mismo tiempo, $\mathrm{su}$ pistis, una constricción moral particularmente fuerte entre los romanos. ${ }^{33}$

En realidad, este discurso público romano en buena medida no sería más que una adaptación al lenguaje político helenístico, cuyo rasgo más evidente era la adopción del tópico clásico de la libertad de los griegos. Sin embargo, es sintomático de la clase de negociaciones y tensiones que estaban en juego en Grecia en el plano de los discursos durante el siglo II a.C. A continuación, veremos algunas de las complejidades del cruce entre las perspectivas griegas y romanas a propósito de una noción importante en el plano de las relaciones interestatales, la philanthropía del vencedor. La misma es una de las piedras angulares del lenguaje político helenístico, pero, lejos de carecer de problemas, el encuentro entre percepciones culturales diferentes se 
convirtió en un espacio para la reflexión y para la explicitación de la propuesta didáctica de Polibio de la utilidad de la moderación del poder imperial romano frente a Grecia.

\section{SULPICIO GALBA, EGINA Y LA PHILANTHROPĹA GRIEGA}

Un breve excerptum del libro Ix menciona una de las disposiciones del procónsul Sulpicio Galba tras la toma de la ciudad aquea de Egina (IX.42.5-8), en el marco de una de las limitadas acciones militares que la flota romana llevó a cabo durante la Primera Guerra Macedónica (214-205 a.C.). El hecho se data usualmente en el 210 a.C., ${ }^{34}$ pero no hay completa seguridad debido a que se desconoce el contexto narrativo previo y, por lo tanto, se ignora si el ataque ocurrió antes o después del intento conjunto del procónsul y del líder etolio Dorímaco de auxiliar a Equina, asediada a su vez por Filipo v. ${ }^{35}$ Ambos problemas, sin embargo, pueden ser pasados por alto en la presente indagación. Nos interesa evaluar la naturaleza del intercambio verbal entre el comandante romano y los prisioneros eginetas, en la medida en que el mismo es la muestra de un verdadero choque entre perspectivas político-culturales diferentes.

Repasemos brevemente la acción. Egina, ciudad miembro de la Confederación aquea, y, por tanto, de la Liga Helénica, había sido conquistada por la flota romana. Encadenados, y a punto de ser embarcados por los vencedores, los ciudadanos cautivos eginetas se dirigieron al comandante romano, Sulpicio Galba, para rogarle que les permitiera buscar "rescate entre las ciudades de linaje afín (pròs tàs syngeneîs póleis perì lýtron)", refiriéndose con ello al conjunto de ciudades dorias del Istmo (Corinto, Argos, Mégara y Sición). ${ }^{36}$ La reacción inicial, sin embargo, fue desestimar el pedido egineta haciendo ver a los prisioneros que, puesto que ya "eran esclavos (doúlous gegonótas)", no tenían derecho a solicitar nada. ${ }^{37} \mathrm{Al}$ día siguiente, con todo, habiendo cambiado de opinión, quizá tras discutir con su consejo privado, Sulpicio Galba congregó nuevamente a los prisioneros para comunicarles que, aunque no merecían piedad, permitiría enviar legados en busca de rescate 
"solo en atención a los griegos restantes... puesto que es habitual entre estos (tôn dè loipôn Hellénon béneka... epeì toûto par' autoîs éthos estin)". 38

Gracias a otros pasajes de la obra, pero también a una inscripción hallada en Acarnania y a la mención por parte de Tito Livio, se sabe que el procedimiento romano en aquella ocasión respondía a las cláusulas del tratado de alianza firmado el año anterior con los etolios, que tenía como objetivo hacer la guerra en Grecia contra Filipo V y sus aliados (c. $212 / 11$ a.C.). ${ }^{39}$ El texto establece un reparto diferenciado del botín: Ciudades y territorios griegos para los etolios, el botín móvil para los romanos, lo que explica seguramente el interés de Sulpicio Galba en que los prisioneros fueran rápidamente embarcados. ${ }^{40}$ Sus objetivos inmediatos, y su necesidad de recursos para presionar más efectivamente a Filipo, pudieron también empujarlo a buscar esclavizar en masa a los eginetas, o, al menos, a intentar cobrar un rescate para contar con recursos que le permitieran proseguir la campaña. ${ }^{41}$

Sospecho que existe un interés específico en detenerse a narrar esta acción marginal. Primero, porque Polibio es un líder aqueo y, como tal, el destino de una importante ciudad federal tiene que haber llamado necesariamente su atención. En segundo lugar, porque el historiador va a volver a tocar el tema más tarde, cuando se mencione el destino de los eginetas en los discursos de Trasícrates de Rodas y de Casandro de Egina, lo que afectará notablemente las relaciones diplomáticas con la dinastía atálida. ${ }^{42}$ En tercer lugar, porque, de acuerdo con los objetivos historiográficos de XI.19a.1, Polibio consideraba que la historia pragmática debía interesarse principalmente por "los combates y guerras, el asedio y la esclavización de las ciudades". El pasaje tenía todo eso, al menos en su estado original. ¿Puede advertirse, además, el juicio del historiador sobre la política romana durante la primera etapa de la intervención en Grecia? Craige Champion ha considerado que Polibio habría buscado allí solo poner de relieve la virtud moral romana en las relaciones interestatales, con un 
acento en la philanthropía del procónsul. ${ }^{43}$ Esta posición debería ser, en mi opinión, objeto de una reconsideración.

Las palabras de Sulpicio Galba revelan, por un lado, una perspectiva plenamente romana, distinguible en su indicación de que los prisioneros eginetas ya "eran esclavos", y que, por ello, carecían de derechos. Posiblemente puede vincularse esto no solo con una concepción del poder absoluto del imperator sobre los despojos, sino también con la idea romana de que los vínculos de parentesco cesaban inmediatamente con la pérdida de la libertad. Además, la posterior admisión de la costumbre griega del rescate entre "parientes" deja ver alguna sensibilidad de Sulpicio Galba por las costumbres griegas, que diferían mucho, sin embargo, del rechazo habitual de los romanos ante la práctica del rescate de prisioneros. ${ }^{44}$ En efecto, los romanos rara vez liberaban a los cautivos, que eran importantes para las relaciones sociales de producción esclavistas italianas, pero también para el prestigio social del comandante romano, que buscaba hacer desfilar a los cautivos durante la celebración de un hipotético triunfo. ${ }^{45} \mathrm{El}$ Digesto bizantino, colección tardía de época de Justiniano, es explícito al respecto: "Los esclavos (servi) se denominan de este modo porque los generales tienen la costumbre de vender a sus prisioneros $\mathrm{y}$, por lo tanto, de preservarlos más que asesinarlos; $\mathrm{y}$ se los llama mancipia, porque son prisioneros (captivi) en manos (manus) de sus enemigos". "Es posible, por lo tanto, que Sulpicio Galba estuviera mostrando cierta flexibilidad con respecto a las prácticas militares romanas.

¿Buscaba Polibio, entonces, resaltar la "humanidad" o "generosidad" del procónsul en aquella oportunidad? De ser así, sería una excepción notable en la carrera del mismo, dado que Sulpicio Galba había actuado durante su campaña con una brutalidad inusitada. Comenzó saqueando Egina y terminó haciendo lo mismo en Dime, en Acaya occidental. Sulpicio Galba puso en práctica una sistemática política de "terrorismo" frente a los aliados griegos de Filipo V, en particular, contra los aqueos. ${ }^{47}$ Una vez reelecto cónsul en 200 a.C., para dirigir una nueva campaña contra el rey de Macedonia, sus métodos no 
experimentaron ningún cambio, tal como parecen atestiguar la sumisión de Oreo o la entrega de Andros a Atalo de Pérgamo. ${ }^{48}$ Este personaje no gozaba, pues, de buena imagen ante la opinión pública griega. ${ }^{49}$ ¿Por qué insertar, entonces, este comentario "positivo"? En ello puede que queden más dudas que certezas.

La "humanidad" de Sulpicio Galba también es problemática desde un punto de vista narratológico. La alusión a la acción humana o generosa (poieîn philánthropon) no es una reflexión del historiador-narrador, sino una apreciación vertida por el propio comandante romano-personaje de la historia. Teniendo en cuenta el modo del relato, y de la regulación de la información narrativa implícita, se trata de la presentación de una perspectiva particular, no necesariamente coincidente con la del historiador-narrador. ${ }^{50} \mathrm{El}$ "dijo", usado para introducir, que los eginetas no merecían que actuara con humanidad [Aiginétais mèn (oudèn) opheílein éphe poiein philánthropon], permite marcar una distancia, en efecto, con el punto de vista del personaje. ${ }^{51}$

En ese sentido, estamos ante un problema historiográfico. Varios trabajos han reconocido en los últimos años la importancia que tienen la visión y la narrativa en la construcción de los distintos puntos de vista de los personajes, del público y del propio historiador. ${ }^{52}$ Adriana Zangara ha advertido, por ejemplo, de qué manera el aspecto visual de las descripciones polibianas pone en juego un poder de "presentación" para hacer "ver los hechos mismos" al lector. El público accedía solo a una experiencia atravesada por los puntos de vista caóticos de múltiples personajes, los que se oponían, por su parte, a la mirada sinóptica, externa, que el historiador analítico desplegaba en sus digresiones autoriales didácticas para ordenar el paisaje de acontecimientos. ${ }^{53}$ Otros estudiosos, como Brian McGing y Nikos Miltsios, se han centrado en la cuestión de las expectativas que buscaba generarse en los lectores, por medio de focalizaciones y provisión de puntos de vista limitados, así como también mediante una distribución desigual de la información entre los personajes. El resultado era una disociación entre las acciones narradas, que aparentan dar acceso no mediado a los "hechos", y las reflexiones del historiador, 
que, por su parte, racionalizaban y daban coherencia final a lo narrado.

En concordancia con estas investigaciones, y en ausencia de una intervención autorial explícita, que implicaba una posible suspensión del juicio, podríamos preguntarnos qué se muestra y por qué es importante hacerlo con la narración de la discusión posterior a la toma de Egina. En principio, está expuesta allí la perspectiva particular de un personaje romano, que reconoce explícitamente la importancia de las costumbres griegas en la diplomacia, y que es consciente, a su vez, del valor de mostrarse sensible a las mismas para alcanzar el éxito de la política romana en el Egeo. Ahora bien, ¿su percepción de "humanidad" es históricamente plausible? ¿Su concepto de philanthropia se ajusta al lenguaje político griego? Desde ya, descartemos una hipotética confusión con la noción de clementia romana. Aunque pudo existir alguna superposición entre ambas nociones, el equivalente griego más exacto de la misma sería la epieikeia, y, además, Sulpicio Galba refiere explícitamente a una costumbre griega y, por lo tanto, introduce su práctica en un marco interpretativo helenístico. ${ }^{54}$ Como intentaremos demostrar, el punto de vista del personaje romano es allí limitado, así como también lo es su comprensión cultural de la philanthropía como piedra angular del lenguaje político helenístico. Su mala comprensión, sin embargo, no debe ser explicada como una consecuencia de la personalidad violenta del procónsul, sino como parte del proyecto didáctico polibiano para la formación de las élites políticas griegas y romanas. ${ }^{55}$

\section{PHILANTHROPÍA Y POLIÍTICA EN EL MUNDO HELENÍSTICO}

En términos generales, philanthropía alude a un conjunto de ideales, actitudes y acciones propias de reyes, funcionarios e, incluso, de individuos particulares que buscan favorecer con sus acciones tanto a comunidades como a personas concretas. ${ }^{56}$ En época helenística, la philanthropía se había vuelto una virtud ideal de reyes, de quienes se esperaba el mantenimiento de la "concordia" (bomónoia) entre sus súbditos, así como también de la seguridad 
dentro de sus territorios. Un rey debía ser "piadoso" (eusebés) y "afectuoso" (philóstorgos), así como también "sabio" (sophós), tener "inteligencia" (phrónesis) y también "dominio de sí mismo" (enkráteia). Con todo, se valoraban más la "magnanimidad" (megalopsychía) y la "generosidad" o "humanidad" (philanthropía), uno de los vocablos más comunes en las inscripciones helenísticas para caracterizar la política real. ${ }^{57}$ El término aparece frecuentemente, incluso, a partir de la baja época helenística para relacionar a la persona honrada con el evergetismo de las élites cívicas o con el del propio emperador, aunque en la alta época helenística tiene una connotación que está más vinculada a la prosperidad asegurada en un contexto de desastre bélico. ${ }^{58}$

ComoLeitmotiv real de la propaganda helenística, la philanthropia puede rastrearse hasta el texto de la carta de Isócrates a Alejandro Magno (342/1 a.C.). ${ }^{59}$ Por su parte, en la Carta a Filócrates, 1 a philanthropia y el afecto hacia el pueblo se destacan como las virtudes cardinales que todo rey debía exhibir: ${ }^{60}$

\section{Es obra de un tirano gobernar con despotismo a quienes le rechazan, causándoles daño por medio del terror, siendo objeto de odio y odiando a los subordinados; de un rey, en cambio, es el dirigir y mandar a quienes le aceptan, haciendo el bien a todos, amado por su beneficencia y su humanidad (dià tèn euergesían kaì philanthropian agapómenon). ${ }^{61}$}

Se advierte en el propio Polibio, entonces, una profunda internalización de este lenguaje político helenístico, ${ }^{62}$ pero también una aceptación de los principios de la reflexión filosófica griega y romana sobre la tiranía como experiencia contraria al reino. ${ }^{63}$ Por ejemplo, Aristóteles consideraba que solo podía llamarse rey a un individuo que hubiera proporcionado beneficios a las ciudades o a los pueblos. ${ }^{64} \mathrm{El}$ concepto polibiano del rey como un individuo cuyo poder es aceptado, y que gobierna a todos con energesía y philanthropia, descansa, por lo tanto, en una apelación a un lenguaje político que el autor comparte con su público.

La apelación a este lenguaje político, como formación conceptual históricamente situada, permite comprender, por 
ejemplo, que Polibio escriba que Escipión Africano había sido saludado por los íberos como "rey". Si seguimos la narrativa en la que está inserto aquel pasaje, la actitud era un resultado lógico de la previa caracterización del líder romano como un hombre naturalmente euergetikòs ("dispuesto a realizar favores"), considerado por ello, por lo tanto, "de carácter real" (basilikós). ${ }^{65}$ En sintonía con esta caracterización, Escipión es representado como un romano particularmente predispuesto a la philanthropía. ${ }^{66}$ Por un lado, exhibe un comportamiento real típicamente helenístico y, por el otro, también romano, por su clementia. Este tipo de transposiciones culturales entre virtudes romanas y griegas no son extrañas en la obra, quizá tampoco en la época. La realidad del intenso contacto cultural en el Mediterráneo, en el que la conectividad, junto con la circulación de bienes, personas, ideas y tecnologías, habían sido aceleradas por la conquista romana, llevaba a que se avanzara hacia cierto lenguaje común. Quizá en esa dirección debamos leer las palabras de Flaminino dirigidas a Alejandro de Etolia, cuando traduce la máxima del parcere subiectis et debellare superbos en clave político-cultural griega al decir que los romanos, al combatir, siempre deben ser corajudos y altivos (bettoménous dè gennaious kaì megalóphronas), mientras que, al vencer, deben comportarse de forma moderada, benigna y humanitaria (nikôntas ge mèn metrious kaì praeis kaì philanthrópous). ${ }^{67}$

Andrew Erskine ha mostrado que la elección de Escipión y de su modelo de construcción de la hegemonía romana sobre los íberos servía en las Historias, además, a los fines de ilustrar la importancia que para todo imperio en crecimiento tenía conseguir primero la éunoia de aliados y súbditos, pero luego preservarla. ${ }^{68}$ Polibio también lo ejemplifica con la trayectoria de la casa real macedónica y la evolución de sus relaciones con los griegos: Filipo v y los etolios, Filipo II y los atenienses y Antígono Dosón y los espartanos. ${ }^{69}$ Filipo II y Antígono Dosón aparecen como perfectos exponentes de la philanthropía, por su comportamiento moderado tras obtener victorias decisivas sobre griegos, mientras que, en el caso de Filipo v, por el contrario, se critica su accionar opuesto a 
las expectativas ideales de cómo debía un rey administrar su victoria.

Esto conduce a pensar finalmente los límites entre ideología y práctica, puesto que, aunque en los hechos, los vencedores no se comportaban moderadamente, sí se esperaba tal actitud en un plano ideal. En la práctica, quien vencía en la guerra tenía total libertad para actuar y decidir el destino de los vencidos, por lo que la esclavización en masa formaba parte permanentemente del horizonte de expectativas. ${ }^{70}$ Solo para mencionar algunos datos, habría que tener en cuenta que, en un estudio sobre la suerte sufrida por la población de 100 sitios fortificados griegos capturados en tiempos de guerra, se ha concluido que en un 59\% de los casos el resultado fue brutal: 25 masacres, 34 esclavizaciones en masa. ${ }^{71}$

Pero la opinión pública griega también representaba un límite para esta supuesta libertad de actuar con los vencidos. Se acostumbraba implementar, en cambio, el cobro de un rescate, lo que podía redundar en un mayor beneficio económico y en un incremento del prestigio social. ${ }^{72}$ La realidad puede ser, de todos modos, bastante más compleja que la imagen construida en un plano idealista. Por ejemplo, según Jenofonte, tras conquistar Babilonia, Ciro el Grande había dicho que era completamente habitual que las personas y sus propiedades pasaran a pertenecer a los vencedores, pero que si esto no ocurría era exclusivamente el resultado de la generosidad (philanthropía) del rey para con los vencidos. $^{73}$ Ahora bien, como señala Pascal Payen, reflexionando sobre lo que está por detrás de la guerra en el pensamiento griego, si bien Jenofonte reconoce la justicia del razonamiento de Ciro, no arenga en la Anábasis a sus propias tropas a emular este comportamiento moderado, sino que acentúa los derechos totales que la victoria supuestamente otorga. ${ }^{74}$

Un comportamiento moderado se atribuye en las Historias también al líder aqueo Arato, al menos durante la primera conquista de Mantinea, en Arcadia, cuyos habitantes se habrían salvado gracias a su generosidad (dià tèn... eis autoùs philanthropian). ${ }^{75}$ $\mathrm{Su}$ posterior esclavización en masa, por el contrario, se presentaba 
como justa con respecto a las mismas supuestas "leyes de la guerra (katà toùs toû polémou nómous hypókeitai patheîn)". ${ }^{76}$ Su punto de vista no fue compartido en la Antigüedad ni por Filarco, ni por Plutarco, para quienes los aqueos en aquella oportunidad no se habían comportado como griegos (ouch Hellenikôs). ${ }^{77}$ Magnánimo y humano (megalopsýchos kaì philanthrópos) había sido, para Polibio, también el comportamiento de Antígono Dosón en Esparta luego de Selasia, cuando tenía la ciudad absolutamente a su merced tras dicha victoria militar y podía actuar como gustara, y eligió el camino de la moderación. ${ }^{78}$

Lamentablemente, en el pasaje sobre los prisioneros eginetas solo se conserva el comportamiento del comandante tras la conquista, y no su acción durante la toma de la ciudad. Esta última acción constituía un motivo muy importante para la historiografía helenística. ${ }^{79}$ En su discurso ante los espartanos, en el mismo libro Ix, Licisco de Acarnania revelaba la vigencia de esta sensibilidad en el caso de las mujeres y niños de Anticira, que habían sido esclavizados por los romanos durante la misma campaña. ${ }^{80} \mathrm{La}$ esclavización en masa de griegos era un horror tan grande que, a menudo, no requería siquiera una explicación adicional. $^{81}$ Grecia continental estaba hasta cierto punto desacostumbrada a esta práctica, que no había observado durante un siglo - o al menos el bache en las fuentes literarias del periodo lo ha ocultado muy bien - entre la destrucción de Tebas y la conquista de Mantinea (335-223 a.C.). ${ }^{82}$

Aunque Polibio no desdeña la introducción de este tipo de recursos dramáticos, su uso debía ser el adecuado para no restar utilidad a la narración histórica. ${ }^{83}$ Inclinado a acentuar la alteridad cultural de las prácticas romanas buscó siempre develar la lógica racional oculta detrás de la aparente brutalidad romana. Así, su objetivo al describir la masacre perpetrada por los romanos en Carthago Nova no se asimilaba al de Tucídides, cuando narraba la caída de Micaleso, sino que, por el contrario, como Erskine ha mostrado, buscaba brindar enseñanzas prácticas a sus lectores griegos. ${ }^{84}$ Su relato de la carnicería de los soldados macedonios tras Cinoscéfalas debe leerse del mismo modo, puesto que, para el 
historiador, habría ocurrido debido a la mala comprensión por parte de los legionarios de la costumbre de rendición de aquellos (bóper éthos estì poieîn toîs Makedósin). ${ }^{85}$ No sería distinta la situación en el intento de deditio de los etolios, que los empujó casi al desastre por no saber exactamente cuál era el sentido de la misma para los romanos (ouk eidótes tína dýnamin échein toûto). ${ }^{86} \mathrm{La}$ misma lógica subyace a la intervención en Egina de Sulpicio Galba, dado que conoce que el rescate de prisioneros es una costumbre de los griegos (epei toûto par' autoîs éthos estín), pero, en cambio, parece ignorar el lenguaje político subyacente. ${ }^{87}$

El sentido político de la philanthropía estaba vinculado con la eficacia, o no, de la estrategia romana en lograr captar el apoyo griego durante la Primera Guerra Macedónica. ¿Por qué los aliados griegos se mantuvieron fieles a Filipo $\mathrm{V}$ en aquella oportunidad? ¿Comprendían los romanos la importancia de la philanthropía como un eficaz mensaje público? La guerra de Cartago contra sus súbditos libios y sus mercenarios (241-237 a.C.), tal como es narrada en las Historias, brinda algunas claves al respecto. Allí, la decisión de los rebeldes de ejecutar a todos los prisioneros cartagineses para cortar cualquier posibilidad de acuerdo con Amílcar Barca actúa como un punto de inflexión en el relato, puesto que los líderes rebeldes advierten el riesgo de la política conciliatoria propuesta por el general cartaginés para dar fin al conflicto: "recelando de la humanidad de Amílcar para con los prisioneros (bypidómenoi tèn Amilkou philanthropian eis toùs aichmalótous) y temiendo que los libios y la masa de mercenarios, atraídos con este proceder, corriesen tras la seguridad que se les ofrecía". ${ }^{88} \mathrm{El}$ general cartaginés había liberado a cuatro mil prisioneros con la única condición de no tomar nuevamente las armas. ${ }^{89}$ La philanthropia representaba, pues, un grave peligro mientras brindara alguna esperanza de seguridad, ${ }^{90}$ lo que muestra por qué la misma era importante para Sulpicio Galba, que intentaba desarticular la alianza griega de Filipo.

¿Pensaba Polibio en las diferencias entre los modos de hacer la guerra entre griegos y romanos y, en consecuencia, buscó acentuarlas discursivamente? Algunos pasajes parecen acentuar 
esta alteridad en el terreno militar, mostrando su faz más brutal. Pero el historiador no buscaba solo esto, sino que apostaba a lograr que el accionar romano consiguiera equipararse a la ideología helenística, volviendo más tolerable así la nueva experiencia de dominio. En ese sentido, no basta con que Sulpicio Galba se refiriera a la philanthropia de su acción, sino que sería necesario ver en qué medida esta expectativa concordaba con el modelo griego predominante en las relaciones interestatales. Por ejemplo, Filipo V pagó él mismo el rescate de sus aliados aqueos esclavizados por los romanos tras el saqueo de Dime. ${ }^{91}$ Esta energesía no fue un gesto altruista, sino que permitió generar obligaciones y lealtades ${ }^{92}$ de hecho, conocemos este beneficio solo porque los dimeos no olvidaron su obligación para con el rey durante la votación aquea para disolver la alianza con aquél. ${ }^{93}$

Llegados a este punto, se impone una aclaración. Polibio exponía una visión idealista de la política interestatal, lo que ha sido sobredimensionado. En su clásico estudio sobre el tratamiento de los prisioneros en Grecia antigua, por ejemplo, Pierre Ducrey creyó advertir una ruptura en las normas tácitas de la guerra helenística con la llegada de Roma. Para ello, citó tres pruebas. La primera era el comportamiento de Sulpicio Galba en Egina, la segunda el saqueo de Epiro por L. Emilio Paulo y la tercera la destrucción de Corinto por L. Mumio. ${ }^{94}$ Parecía un verdadero choque entre dos modos de concebir la guerra, entre un modo atroz (romano) y uno mucho más reglado (griego). Los tres hechos aducidos, sin embargo, provienen directa o indirectamente de las Historias. ${ }^{95}$ ¿La llegada de Roma representó una verdadera ruptura?

Ducrey no está solo en esta perspectiva, que se expone recurrentemente. Para William Tarn, por ejemplo: "el mundo griego, acostumbrado a los métodos de la guerra macedónica, que se habían hecho relativamente humanos, vio con miedo o ira lo que hacían los romanos en una ciudad ocupada”. Señala, además, que Filipo V "tomó Lisimaquia, Calcedonia y Cíos, y destruyó esta última con furia que más tarde desplegaría también en Abidos y Maronea; estaba probando los métodos romanos, y provocó 
desconfianza general y hasta odio". 96 También Claire Préaux pensaba en una ruptura en los métodos de la guerra con la llegada de los romanos. ${ }^{97}$ Pero el mundo helenístico estuvo también signado por la guerra y la violencia, que hundían sus raíces en las necesidades económicas y políticas de las grandes monarquías, pero también en los impulsos de las póleis más modestas. ${ }^{98} \mathrm{La}$ brutalidad helenística no difería necesariamente de la romana, excepto en la escala e intensidad. ${ }^{99}$

Más que reflejar una tendencia en el mundo griego antiguo, estas opiniones son parte de una reflexión contemporánea sobre la supuesta "humanización" de la guerra en el mundo helenístico, tesis que bregó por atribuir un carácter vinculante a las llamadas "leyes de la guerra" en la Antigüedad. Esta postura fue alentada por algunos historiadores, que, ante los horrores de dos guerras mundiales, comenzaron a buscar ejemplos de cómo los griegos habían logrado temperar los efectos de la violencia en diversas circunstancias. Esta era una faceta importante del "milagro griego", que podía ser un ejemplo edificante para el mundo contemporáneo. ${ }^{100}$ Para reconocer los límites de esta perspectiva baste tener en cuenta, por ejemplo, que en Etolia dos tercios de los esclavos manumitidos sobre los que existe algún tipo de registro eran, en efecto, de origen griego. ${ }^{101}$

¿Qué tipo de beneficio concedió, entonces, Sulpicio Galba a los eginetas? Liberación de prisioneros sin rescate era una estrategia usual de prestigio en el mundo griego. ${ }^{102}$ Sin embargo, la acción del comandante romano revela, por lo menos, su miopía política en un momento en el que necesitaba comenzar a competir activamente con la hegemonía macedónica en Grecia. El beneficio concedido, que era permitirles marchar en búsqueda de rescate, era comparativamente magro.

El contraste con otras figuras históricas en la obra puede ofrecer mayor luz. Filipo II aparece allí como un ejemplo de líder que, actuando lógica y racionalmente, conduce exitosamente su política en Grecia. ${ }^{103}$ Ello ocurrió cuando, tras Queronea (338 a.C.), consiguió la éunoia ("adhesión") de los atenienses derrotados porque "liberó a los prisioneros de guerra sin exigir rescate (choris 
lítron aposteilas toùs aichmalótous)". ${ }^{104}$ Esto contribuyó además a cimentar su reputación panhelénica de philanthropía. ${ }^{105}$ No es necesario discutir aquí la historicidad de esta afirmación, por lo demás bastante dudosa, sino advertir su peso en tanto ideal de comportamiento del vencedor propuesto en las Historias. ${ }^{106} \mathrm{El}$ discurso de Cleneas revela, en efecto, que la política de Filipo no había sido un gesto altruista ${ }^{107}$ pero no debemos perder de vista que el concepto de virtud polibiano incluía la necesidad de ser un individuo con un "cálculo considerablemente prudente, incluso egoísta" ${ }^{108}$ Como Marie-Rose Guelfucci ha señalado, que se eligiera caracterizar a Filipo utilizando el término anchinoia no es casual, puesto que es una virtud apreciada no solo en el plano moral, sino también en el práctico. ${ }^{109}$ Se ofrecía al público, por lo tanto, como un ejemplo de construcción y ejercicio responsable de la hegemonía, imitable por los romanos en su relación presente con los griegos. ${ }^{110}$

Sulpicio Galba, insistimos, había garantizado a los eginetas un favor pequeño, al menos comparado con los ejemplos de Arato, Antígono Dosón y, particularmente, Filipo II. En esos casos, Polibio mismo se encarga de juzgar y encuadrar sus acciones como "humanas" o "generosas". Adicionalmente, un problema importante es que se desconoce si la acción del procónsul permitió finalmente, o no, la salvación de los eginetas. Solo se sabe que la isla fue entregada a los etolios y que estos la vendieron luego a Atalo I, que necesitaba una base naval en el área (que contrapesara la presencia ptolemaica y antigónida). Su probable final no parece, sin embargo, haber sido feliz. El discurso de Trasícrates de Rodas deja entrever su infortunio (tôn talaipóron Aiginetôn). ${ }^{111}$ La misma expresión vuelve a aparecer en una ulterior intervención de Casandro de Egina ante la asamblea aquea (185 a.C.) (bóte Póplios Solpikios... exendrapodísato toùs talaipórous Aiginétai). ${ }^{112}$ Más allá del contexto retórico, debemos suponer que la intervención del procónsul no habría podido impedir la esclavización en masa. ${ }^{113}$ 


\section{A MODO DE CIERRE}

Entonces, ¿por qué Sulpicio Galba consideró que actuaba con philanthropia? Lo más probable es que Polibio, al recurrir a un personaje que no gozaba de buena fama en el mundo griego, diera a entender a sus lectores que en el dramático momento de contacto militar entre romanos y griegos ambos pueblos interpretaban la philanthropia de formas bastante diferentes. Polibio podía buscaba explicar, evitando reducir al mismo tiempo la atmósfera de alteridad, ciertos aspectos de la cultura romana que resultaban chocantes para el público griego. Al mismo tiempo, perseguía formar a los líderes políticos romanos a través de la provisión de ejemplos de conducta moderada. De hecho, la construcción de Sulpicio Galba no es completamente negativa, puesto que se le muestra al menos dispuesto a comportarse de acuerdo con lo que considera que son las prácticas diplomáticas griegas. El objetivo de obtener botín móvil era un imperativo particular para los romanos, de acuerdo con el tratado que habían firmado con los etolios. Los relatos de las tomas de Morgantina, Siracusa y Tarento parecen mostrar asimismo que los romanos no gozaban de buena fama entre los griegos. ${ }^{114} \mathrm{~A}$ su vez, el problema de la esclavización de griegos era un tema tan sensible para la opinión pública en Grecia, que fue utilizado activamente en la oratoria hostil a Roma, por ejemplo, por Licisco de Acarnania ${ }^{115} \mathrm{o}$ Trasícrates de Rodas ${ }^{116}$. Allí, el comportamiento de los romanos se definía allí retóricamente como propiamente bárbaro (omòn eînai tò toioûto kai barbarikón), quizá, a esa altura, simplemente como "no griego". 117

Como Champion ha sugerido, es probable que esta atribución de barbarie a los romanos en discurso indirecto, en boca de tres personajes griegos, constituyera un vehículo para dar voz a una línea de hostilidad hacia Roma, compartida por una buena parte del público griego al que se dirigía Polibio. ${ }^{118}$ Champion se pregunta además sobre dos cuestiones. Primero, sobre las posibilidades reales de hallar versiones impresas de estos discursos y, en tal sentido, sobre la ilusión historicista de poder acceder a los textos originales, no intervenidos de ninguna manera por el 
historiador antiguo para incorporar su propia perspectiva $y$ comprensión de los hechos. ${ }^{119}$ Segundo, sobre la inutilidad de considerar el carácter prorromano o antirromano prima facie de estos discursos, puesto que este tipo de abordaje desviaría el foco de la cuestión de una obra en condiciones de ser leída tanto por griegos como por romanos. ${ }^{120} \mathrm{La}$ complejidad intercultural debe ser tenida, por lo tanto, muy en cuenta.

A estas dos preocupaciones podríamos añadir la importancia de plantear una pregunta por los efectos situacionales que el historiador, en tanto narrador, buscaba generar en sus lectores, griegos y romanos, y cómo ubicaba para ello a sus distintos personajes en la posición de observadores, pero siempre con limitados puntos de vista. Esto creaba un texto con perspectivas, percepciones e interpretaciones variadas, que solo podían conciliarse y ordenarse mediante la intervención del historiador como narrador omnisciente. ${ }^{121}$ En ese sentido, es útil reconsiderar la distancia entre lo expuesto por Sulpicio Galba, la propia interpretación que hace de su propia acción, y lo reflexionado, a su vez, por el historiador con respecto a Filipo II. Allí, Polibio construía y proveía a los lectores un modelo de comportamiento hegemónico válido para todo poder en sus primeras etapas y, por lo tanto, al hacerlo, tenía un ojo puesto también en los romanos y en su relación con el mundo griego. El comportamiento de Sulpicio Galba con los prisioneros eginetas, aunque formalmente en concordancia con el lenguaje político helenístico, no se adaptaba completamente al modelo trazado por Filipo II, revelando una cierta incapacidad del romano para reconocer las implicancias completas de la philanthropía.

Las diferencias culturales, la frontera entre griegos y romanos, no eran infranqueables en el camino de la construcción de una hegemonía exitosa. Polibio consideraba que un comandante romano podía perfectamente incorporar el lenguaje político helenístico tal como Escipión Africano había hecho durante su campaña en Iberia. El historiador aqueo no solo creía que una adaptación a este lenguaje era posible, como la práctica de Flaminino había revelado con su ideal de que "la más bella de las 
Calíope: Presença Clássica | 2020.2 . Ano XXXVII . Número 40 (separata 5)

empresas" era luchar "por la libertad de Grecia", ${ }^{122}$ sino que también su obra estaba en gran medida pensada para orientar las acciones de sus lectores romanos por el camino de esa moderación imaginaria. 
Percepciones politico-culturales encontradas [...] | Álvaro M. Moreno Leoni

ABSTRACT

This essay is an interpretation of a fragmentary passage of the Histories of Polybius (IX.42.5-8), which narrates the final episode of Aegina's capture during the First Macedonian War (210 BC). The encounter between Greek and Roman perspectives on the notion of philanthropia is stressed in order to show its importance in the context of Polybius' conceived lesson on the moderate exercise of power.

KEYWORDS

Polybius; philanthropia; Greek historiography; Didactics. 
REFERENCIAS

AUSTIN, Michel. Hellenistic Kings, the War and the Economy. Classical Philology, v. 36.2, p. 450-466, 1986.

BaLot, Ryan. Polybius' Advice to the Imperial Republic. Political Theory, v. 38.4, p. 483-509, 2010.

Baronowski, Donald. Polybius and Roman Imperialism. London: Bristol Classical Press, 2011.

BIELMAN, Anne. Retour à la liberté: libération et sauvetage des prisoniers en Grèce ancienne: recueil d'inscriptions honorant des sauveteurs et analyse critique. Paris: De Boccard, 1994.

BRADLEY, Keith. Esclavitud y sociedad en Roma. Barcelona: Península, 1998 (1994).

BRAndstäter, Franz. Die Geschichten des Aetolischen Landes, Volkes und Bundes. Berlin: Reimer, 1844.

BRISCOE, John. A Commentary on Livy. Books xxxI-xxxIII. Oxford: Clarendon Press, 1973.

Broughton, Thomas. The Magistrates of the Roman Republic, v. 1. New York: American Philological Association, 1951.

BURTON, Paul. Friendship and Empire: Roman Diplomacy and Imperialism in the Middle Republic. Cambridge: Cambridge University Press, 2011.

CHAmpion, Craige. The Nature of Authoritative Evidence in Polybius and the Speech of Agelaus at Naupactus. Transactions of the American Philological Association, v. 127, p. 111-128, 1997.

CHAMPION, Craige. Histories 12.4b.1-4c.1: An Overlooked Key to Polybios' Views on Rome. Histos, v. 4, p. 1-5, 2000.

CHAMPIOn, Craige. Romans as BAPBAPOI: Three Polybian Speeches and the Politics of Cultural Indeterminacy. Classical Philology, v. 95 (4), p. 425-444, 2000a.

CHAMPIOn, Craige. Cultural Politics in Polybius' Histories, Berkeley, University of California Press, 2004.

CHANiotis, Angelos. Die Verträge zwischen kretischen Poleis in der hellenistischen Zeit. Stuttgart: Franz Steiner, 1996.

CLARKE, Katherine. Polybius and the Nature of late Hellenistic Historiography. In: Santos yanguas, Juan; torregaray pagola, Elena. Polibio y la Península Ibérica. Vitoria, Universidad del País Vasco, 2005, p. 69-87. 
Davidson, James. The Gaze in Polybius' Histories. The Journal of Roman Studies, v. 81, p. 10-24, 1991.

DE ROMILly, Jacqueline. La douceur dans la pensée grecque. Paris: Les Belles Lettres, 1979.

DE ROMILly, Jacqueline. Thucydide et l'impérialisme athénien. Paris: Les Belles Lettres, 1947.

DEININGER, Jürgen. Der politische Widerstand gegen Rom in Griechenland, 217-86 v. Chr. Berlin: Walter de Gruyter, 1971.

DMiTRIev, Sviatoslav. The Greek Slogan of Freedom and Early Roman Politics in Greece. Oxford: Oxford University Press, 2011.

Dubuisson, Michel. La vision polybienne de Rome. In: verdin, Herman et al. Purposes of History: Studies in Greek Historiography from the 4th to the 2nd Centuries BC. Peeters: Leuven, 1990, p. 233-243.

Dubuisson, Michel. Le latin de Polybe. Les implications historiques d'un cas de bilingüisme. Paris: Klincksieck, 1985.

DUCREY, Pierre. Les fortifications grecques: rôle, fonction, efficacité. In: LERICHE, Pierre; TREZINY, Henri. La fortification dans l'histoire du monde grec: Paris: CNRS, 1982, p. 133-142.

DUCREY, Pierre. Le traitement des prisonniers de guerre dans la Grèce antique. Des origines a la conquête romaine. Paris: De Boccard, 1968.

ECKSTEIN, Arthur. Hannibal at New Carthage: Polybius 3.15 and the Power of Irrationality. Classical Philology, v. 84, p. 1-15, 1989.

ECKSTEIN, Arthur. T. Quinctius Flamininus and the Campaign against Philip in 198 B.C. Phoenix, v. 30.2, p. 119-142, 1976.

ECKSTEIN, Arthur. Mediterranean Anarchy, Interstate War and the Rise of Rome. Berkeley: University of California Press, 2006.

eckstein, Arthur. Moral Vision in the Histories of Polybius. Berkeley: University of California Press, 1995.

ECKSTEIN, Arthur. Senate and General. Individual Decision-Making and Roman Foreign Relations, 264-194 B.C. Berkeley: University of California Press, 1987.

errington, Robert. Philopoemen. Oxford: Clarendon Press, 1969.

ERSKINE, Andrew. O Brother, where art thou? Tales of Kinship and Diplomacy. In: ogden, Daniel. The Hellenistic World: New Perspectives. London: Duckworth, 2002, p. 97-115. 
ERSKINE, Andrew. Polybios and Barbarian Rome. Mediterraneo Antico, v. 3.1, p. 165-182, 2000.

ERSKINE, Andrew. Spanish Lessons: Polybius and the Maintenance of Imperial Power. In: Santos yanguas, Juan; torregaray pagola, Elena. Polibio y la Península Ibérica. Vitoria: Universidad del País Vasco, 2005, p. 229-243.

FERRARY, Jean-Louis. Philhellénisme et impérialisme. Aspects idéologiques de la conquête romaine du monde hellénistique, de la seconde guerre de Macédoine à la guerre contre Mithridate. Paris: École Française de Rome, 1988.

Fustel De Coulanges, Numa. Polybe ou la Grèce conquise par les romains. Amiens: Imprimerie de T. Jeunet, 1858.

GARLAn, Yvon. War, Piracy and Slavery in the Greek World. In: FINLEY, Moses, Classical Slavery. NJ. Cass, London-Totowa: Psychology Press, 1987, p. 7-21.

GAUTHIER, Philippe. Les cités grecques et leurs bienfaiteurs: Paris: École Française d'Athènes, 1985.

GENETTE, Gérard. Figures III. Paris: Éditions du Seuil, 1972.

Gigante, Marcello. La crisi di Polibio. Parola del Passato, v. 6, p. 33-53, 1951.

GLOTZ, Gustave. Le droit des gens dans L'Antiquité grecque. Mémoires présentés pars divers savants à l'Académie des Inscriptions et Belles Lettres, v. 13.1, 1923, p. 91-103.

Grainger, John. Aitolian Prosopographical Studies. Leiden: Brill, 2000.

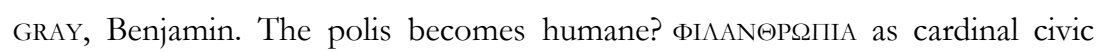
virtue in later hellenistic honorific epigraphy and historiography. Studi Ellenistici, v. 27, p. 137-162, 2013.

GRAY, Benjamin. Scepticism about Community: Polybius on Peloponnesian Exiles, Good Faith (Pistis) and the Achaian League. Historia, v. 62.3, p. 323360, 2013a.

GRETHLEIN, Jonas. Experience and Teleology in Ancient Historiography: Futures Past from Herodotus to Augustine. Cambridge: Cambridge University Press, 2013.

GRUEn, Erich. The Hellenistic World and the Coming of Rome. Berkeley: University of California Press, 1986 (1984).

Guelfucci, Marie-Rose. Polybe et les mises en scène de la Tychè. Dialogues d'Histoire Ancienne, suppl. 4.2, 2010, p. 439-468. 
GUelfucci, Marie-Rose. Polybe, le regard politique, la structure des Histoires et la construction du sens. Cahiers des Études Anciennes, v. 47, p. 329-357, 2010a.

HARRIS, William. War and Imperialism in Republican Rome. Oxford: Clarendon Press, 1985 (1979).

HARris, William. Roman Power. A Thousand Years of Empire. Cambridge: Cambridge University Press, 2016.

Herrmann, Peter. Antiochus der Grosse und Teos. Anadolu, v. 9, p. 29-159, 1965.

HUNGER, Herbert. $\Phi \iota \lambda \alpha \nu \theta \varrho \omega \pi$.aEine griechische Wortprägung auf ihrem Wege von Aischylos bis Theodorus Merochites. Wiener Anzeiger, v. 100, p. 1-20, 1963.

KIECHLE, Franz. Zur Humanität in der Kriegführung der griechischen Staaten. Historia, v. 7.2, p. 129-156, 1958.

LA Roche, Paul. Charakteristik des Polybios. Leipzig: Teubner, 1857.

LAFOND, Yves. La mémoire des cités dans le Péloponnèse d'époque romaine. IIe siècle avant J.-C.-IIIe siècle après J.-C. Le Harpe: Presses Universitaires de Rennes, 2006.

Lehmann, Gustav. The Ancient Greek History in Polybius' Historiae: Tendencies and Political Objectives. Scripta Classica Israelica, v. 10, p. 66-77, 1989/90.

LÉVÊCQUE, Pierre. La guerre à l'époque hellénistique. In: VERNANT, Jean-Pierre. Problèmes de la guerre en Grèce ancienne. Paris: Mouton, p. 261-287, 1968.

LÉVY, Edmond. La tyrannie chez Polybe. Ktèma, v. 21, p. 43-54, 1996.

MA, John. Fighting Poleis of the Hellenistic World. In: van weEs, Hans. War and Violence in Ancient Greece. London: Duckworth, p. 337-376, 2000.

MA, John. Antiochos III and the Cities of Western Asia Minor. Oxford: Oxford University Press, 1999.

MAIER, Felix. "Überall mit dem Unerwarteten rechnen". Die Kontingenz historischer Prozesse bei Polybios. München: C.H. Beck, 2012.

MARINCOLA, John. Polybius, Phylarchus, and 'Tragic History': A Reconsideration. In: GIBSON, Bruce; HARRISON, Thomas. Polybius \& his World. Essays in Memory of F. W. Walbank. Oxford: Oxford University Press, 2013, p. 73-90.

MARTIN, Hubert. The Concept of Philanthropia in Plutarch's Lives. American Journal of Philology, v. 82, p. 164-175, 1961. 
MARTÍNEZ LACY, Ricardo. $\quad \theta q \alpha \nu \quad \mu \mu \alpha$ Polybius and his Concept of Culture, Klio, v. 73.1, p. 83-92, 1991.

MCGING, Brian. Polybius' Histories. Oxford, Oxford University Press, 2010.

MiLtsios, Nikos. The Perils of Expectation: Perception, Suspense and Surprise in Polybius' Histories. In: GRETHLEIN, Jonas; ReNGaKos, Antonios. Narratology and Interpretation. Berlin: Walter de Gruyter, p. 481-506, 2009.

miltsios, Nikos. The Shaping of Narrative in Polybius. Berlin: Walter de Gruyter, 2013.

Mioni, Elpidio. Polibio. Padova: Cedam, 1949.

momigliano, Arnaldo. Alien Wisdom. The Limits of Hellenization. Cambridge: Cambridge University Press, 1975.

MOORE, John. The Manuscript Tradition of Polybius. Cambridge: Cambridge University Press, 1965.

MORENO LEONI, Álvaro. Interpretando el mundo romano: retórica de la alteridad, público y cultura griega en las Historias de Polibio. Gerión, v. 30, p. 63-90, 2012.

MORENo LEONI, Álvaro. Polibio, el mundo helenístico y la problemática cultural: Algunas líneas de reflexión en los últimos veinte años. De Rebus Antiquis, v. II.2, p. 123-151, 2012a.

MOREno LEONI, Álvaro. The Failure of the Aetolian Deditio as a Didactic Cultural Clash in the Histories of Polybius (20.9-10). Histos. The On-line Journal of Ancient Historiography, v. 8, p. 146-179, 2014.

MUCCIOLI, Federicomaria. Gli epiteti ufficiali dei re ellenistici. Stuttgart: Franz Steiner, 2013.

MUSTI, Domenico. Polibio e la storiografia romana arcaica. In: GABBA, Emilio. Polybe. Vandoeuvres: Fondation Hardt, 1974, p. 105-139.

MUSTI, Domenico. Polibio e l'imperialismo romano. Napoli: Liguori, 1978.

NICHOLSON, Emma. Hellenic Romans and Barbaric Macedonians: Polybius on Hellenism and Changing Hegemonic Powers. Ancient History Bulletin, v. 34.1-2, p. 38-73, 2020.

PALTi, Elías. De la historia de 'ideas' a la historia de los ‘lenguajes políticos'. Las escuelas recientes de análisis conceptual. El panorama latinoamericano. Anales - Instituto Ibero Americano, v. 7-8, p. 63-81, 2005.

PAUl, George. 'Urbs Capta'. Sketch of an ancient literary motif. Phoenix, v. 36.2, p. 144-155, 1982. 
Percepciones politico-culturales encontradas [...] | Álvaro M. Moreno Leoni

PAYEN, Pascale. Les revers de la guerre en Grèce ancienne. Paris: Belin, 2012. PÉDECH, Paul. La méthode historique de Polybe. Paris: Les Belles Lettres, 1964.

pianezzola, Emilio. Traduzione e Ideologia. Livio interprete di Polibio. Bologna: Patron, 1969.

PRÉAUX, Claire. La paix à l'époque hellénistique. In: La paix, Recueils de la Société Jean Bodin pour l'histoire comparative des sociétés, v. XIV.1, p. 227-301, 1961.

PRÉAUX, Claire. El mundo helenístico. Grecia y Oriente (323-146 a. de C.), v. I. Barcelona: Editorial Labor, 1984 (1978).

PRITCHetT, William. The Greek State at War, v. V. Berkeley: University of California Press, 1991.

rostovtzeff, Mikhail. The Social and Economic History of the Hellenistic World. Oxford: Clarendon Press, 1998 (1941).

SCHUBART, Wilhelm. Das hellenistische Königsideal nach Inschriften und Papyri. Archiv für Papyrusforschung, v. 12, p. 1-26, 1936-1937.

SCOTT, James. Los dominados y el arte de la resistencia. Discursos ocultos. México: Ediciones Era, 2004 (1990).

TARN, William; Griffith, Guy. La Civilización Helenística. México: FCE, 1969 (1952).

THORnton, John. Polibio e Roma. Tendenze negli studi degli ultimi anni (I). Studi Romani, v. 52.1-2, p. 108-139, 2004.

Thornton, John. Polibio e Roma. Tendenze negli studi degli ultimi anni (II). Studi Romani, v. 52.3-4, p. 508-525, 2004a.

THORNTON, John. Barbari, Romani e Greci. Versatilità di un motivo polemico nelle Storie di Polibio. In: Migliario, Elvira; TroiAnI, Lucio; ZECCHINI, Giuseppe. Società indigene e cultura greco-romana. Roma: L'Erma di Bretschneider, 2010, p. 45-76.

THORnton, John. Polibio e gli imperi (Filippo v, Cartagine e altri paradeigmata). Dialogues d'Histoire Ancienne, Suppl. 9, p. 145-164, 2013.

Thornton, John. Polybius in Context: The Political Dimension of the Histories. In: GibSON, Bruce; HARrison, Thomas. Polybius \& his World. Essays in Memory of F. W. Walbank. Oxford: Oxford University Press, 2013a, p. 213229.

virgilio, Biagio. Polibio, il mondo ellenistico e Roma. Athenaeum, v. 95, p. 4973, 2007. 
WALbanK, Frank. Monarchies and Monarchic Ideas. CAH vir.1. Cambridge: Cambridge University Press, 2006 (1984), p. 62-100.

Walbank, Frank. A Historical Commentary on Polybius, v. I-III. Oxford: Clarendon Press, 1999 (1957-1979).

WAlBAnK, Frank. Philip v of Macedon. Hamden: Archon Books, 1967 (1940).

Weissenberger, Michael. Das Imperium Romanum in den Proömien dreier griechischer Historiker: Polybios, Dionysios von Alikarnassos und Appian. Rheinische Museum für Philologie, v. 145, p. 262-281, 2002.

WELLES, Charles. Royal Correspondence of the Hellenistic Age. A Study in Greek Epigraphy. New Haven: Yale University Press, 1934.

WelweI, Karl. Könige und Königtum im Urteil des Polybios. Herbede (Ruhr): Graphische Betribe Hans Kolb, 1963.

WELWEI, Karl. Sub Corona Vendere. Quellenkritische und Studien zu Kriegsgefangenschaft Sklaverei in Rom bis zum Ende Hannibalkrieges. Stuttgart: Franz Steiner, 2000.

wiCkHAM, Jason. The Enslavement of War Captives by the Romans to 146 BC. PhD Dissertation. Liverpool: University of Liverpool, 2014.

ZANGARA, Adriana. Voir l'histoire: théories anciennes du récit historique (IIe siècle avant J.-C.- II siècle après J.-C. Paris: Vrin/EHESS, 2007. 
${ }^{1}$ Agradezco los comentarios de los dos evaluadores anónimos de la revista. Una primera versión del trabajo fue discutida en 2014 en el marco del Seminario de Historia Antigua (UnAM, México), dirigido por Ricardo Martínez Lacy, a quien agradezco por el fecundo intercambio de ideas en aquella oportunidad. El artículo también se benefició de las sugerencias de los demás participantes del coloquio "Formas de alienación política: Constricción sin violencia y violencia del Estado. El paradigma romano (siglos II-I a.C.)" (Universidad del Franco Condado, Francia), al que fui generosamente invitado por Marie-Rose Guelfucci. Estoy en deuda particularmente con John Thornton, quien me llamó la atención sobre cuestiones importantes para la argumentación aquí expuesta. Los problemas que quedan en el texto, desde luego, son responsabilidad absolutamente propia del autor. La investigación se benefició del financiamiento de los proyectos SECYT-UnC Consolidar 2018-2021 у РіCT 2016 N¹396, que dirijo.

2 MUSTI, 1978, p. 13, 41-42; HARRIS, 1985, p. 1; GRUEN, 1986, p. 343-384; Cfr. BARONOWSKI, 2011, p. 11-13.

${ }^{3}$ Cfr. POlibio, Historias, i.1.6; 4.4; vi.2.3; xxxix.8.7; BARONOwSKI, 2011, p. 197, n. 2. En adelante, en todas las referencias a la obra de Polibio solo aparece el pasaje, sin abreviatura del nombre del autor. La edición utilizada es la de Teubner de Th. BÜTTNER-WOBST.

${ }^{4}$ I.1.5.

${ }^{5}$ III.4.7. El minado del télos original de su obra, el año 168/7 a.C., mediante este nuevo proemio, demuestra la importancia que tiene para el historiador aqueo "el poder de la retrospectiva (the power of hindsight)", como un punto de vista superior desde el cual el historiador "puede ver y construir líneas que están más allá del agarre de los agentes históricos" (GRETHLEIN, 2013, p. 267). Esto opera de muchos modos, pero sobre todo es posibilitado porque la historia se mira desde el presente del autor, hacia el cual converge la narración de los hechos y también las acciones de los personajes, que carecen de una perspectiva completa. Ver: GRETHLEIN, 2013, p. 224-267, con la importancia de: V.32.

${ }^{6}$ MILTSIOS, 2013, p. 28, 53-57; BARONOWSKI, 2011, p. 67-71.

${ }^{7}$ ECKSTEIN, 1995, p. 233-236.

${ }^{8}$ Cfr. THORNTON, 2004; 2004a; MORENO LEONI, 2012a.

${ }^{9}$ BARONOWSKI, 2011.

10 MORENO LEONI, 2012. A mi entender, esto fue observado primero por MARTÍNEZ LACY, 1991.

${ }^{11} \mathrm{La}$ tesis de una identificación de Polibio con Roma, producto de una profunda "conversión" política, espiritual e, incluso, cultural, es antigua. Basta revisar al respecto: FUSTEL DE COULANGES, 1858; GIGANTE, 1951, p. 34; Dubuisson, 1985, 1990. Este último ha llevado más lejos su propuesta, señalando que es posible advertir una latinización del griego de Polibio y que esto habría conducido, con el tiempo, a una romanización de su mentalidad: DUBUISSON, 1985, p. 288.

12 GUELFUCCI, 2010a, p. 330-331 (alude a IX.10.7-10; Xxxi.2.5-8; Xxxvi.9); CLARKE, 2005, p. 85.

13 WEISSENBERGER, 2002, p. 279. El complejo proceso de integración de la cultura romana y griega recién comenzaba: "Para el siglo II a.C., la época de Polibio, hablar de cultura grecorromana sería prematuro": THORNTON, 2010, p. 45.

${ }^{14}$ Problema estudiado de forma magistral por CHAMPION (2004). En el pasado, he abordado esta cuestión en diversas oportunidades. Ahora, recomiendo también el trabajo de NICHOLSON (2020), que integra la representación del poder hegemónico con los aspectos culturales derogatorios.

15 BARONOWSKI, 2011, p. 94-97. 
${ }^{16}$ Idem, ibidem, p. 15-60.

${ }^{17}$ V.106.5; DE ROMILLY, 1947, p. 73

18 XXXVIII.2.8-9.

${ }^{19}$ ERSKINE, 2005; THORNTON, 2013 a.

${ }^{20} \mathrm{MA}, 1999$.

${ }^{21}$ Idem, ibidem, p. 187-188.

${ }^{22}$ HERRMANN, 1965, n 24, 1l. 6-8; WELLES, 1934, n 52, p. 7-8; GAUTHIER, 1985, p. 40-41.

${ }^{23}$ Sylloge Inscriptionum Graecarum, $3^{\circ}$ ed., 702, 11. 7-8.

${ }^{24}$ FERRARY, 1988, p. 124-132.

${ }^{25}$ THORNTON, 2013.

26 "Polibio, el consejero de Escipión Emiliano, se puede ver un poco como el consejero de Roma; y era su rol de aqueo que le aconsejaba la delicadeza": DE ROMILLY, 1979, p. 247; FERRARY, 1988, p. 423; ERSKINE, 2005; BALOT, 2010.

${ }^{27}$ MOMIGLIANO, 1975, p. 36.

${ }^{28}$ Los "lenguajes políticos", claves para la historia intelectual, se entienden como formaciones conceptuales completamente históricas, es decir, claramente contingentes y singulares y en las que es necesario prestar atención a sus condiciones de enunciación: PALTi, 2005, p. 71. Ver sobre los discursos ocultos: SCOTT, 2004 (1990).

${ }^{29}$ THORNTON, $2013 \mathrm{a}$, p. 227.

${ }^{30}$ Idem, ibidem, p. 229.

31 TITO LIVIO, XXXV.51.6-7.

${ }^{32}$ PLUTARCO, Flaminino, 16.5-7.

${ }^{33}$ xxiv.13.3. Cfr. 1 Macabeos. 8.12-13.

${ }^{34}$ Sobre los problemas para la datación del acontecimiento y proveniencia de los excerpta gnómicos de Constantino (manuscrito “M”): WALBANK, 1999, HCP II, p. 186; MOORE, 1965, p. 132-133.

${ }^{35}$ WALBANK, 1999, HCP II, p. 186.

${ }^{36}$ IX.42.5. Como "antídoto" contra la esclavización en masa: GARLAN, 1987, p. $13-15$.

${ }^{37}$ IX.42-6.

${ }^{38}$ IX.42.8. Haciendo uso de la relativa libertad de los comandantes romanos para establecer acuerdos: ECKSTEIN, 1987.

39 Inscriptiones Graecae, IX.1, 241; TITO LIVIO, XXVI.24.8-13. Cfr. IX.37.6-39.7; XI.5.2-8; TITO LIVIO, XXVI.26.3.

${ }^{40} \mathrm{La}$ isla es entregada a los etolios, quienes a su vez la venden a Atalo de Pérgamo por 30 talentos (XI.5.8; XXII.8.9-10). El objetivo romano del botín es claro también durante el saqueo de Dime: PAUSANIAS, VII.17.5.

${ }^{41}$ WELWEI, 2000, p. 120.

${ }^{42}$ XI.5.8; XXII.8.9.

${ }^{43}$ CHAmpion, 2004, p. 147. Lo que Sulpicio Galba dice es poieîn philánthropon (IX.42.8). Podría haber quizá una diferencia con términos que más claramente aluden a la expresión de una virtud como philanthropia, philánthropos y philanthrópos: GRAY, 2013, p. 142-143. Sin embargo, por el contexto, que no es el otorgamiento de un bien material, creemos que está ligado a la idea de humanidad o generosidad con los prisioneros.

${ }^{44}$ BRADLEY, 1998, p. 41. El rescate de prisioneros con un sentido parental más restringido existía entre los romanos: cum ab suis non redimerentur (TITO LIVIO, XXXIV.50.5). Rescate resistido por los romanos: WICKHAM, 2014, p. 50-53.

${ }^{45}$ BRADLEY, 1998, p. 38-39.

${ }^{46}$ Digesto, I.5.4.2. 
47 Sobre esta campaña de Sulpicio Galba: Ix.42.5-8; XI.5.8 (Oreo y Egina); PAUSANIAS, VII.17.5; TITO LIVIO, XXXII.22.10; APIANO, Guerras Macedónicas, 7 (Dime). La idea de "terrorismo" como instrumento tanto de Sulpicio Galba, como de Flaminino: ECKSTEIN, 1976, p. 126. Sobre Sulpicio Galba: DEININGER, 1971, p. 32-34; BROUGHTON, 1951, p. 280, 287, 292, 296, 300.

${ }^{48}$ FERRARY, 1988, p. 51.

${ }^{49}$ GRUEN, 1986, p. 205-206. Cfr. IX.42.5-8; XI.5.6-8; APIANO, Guerras Macedónicas, 3.1, 7; PAUSANIAS, VII.17.5; TITO LIVIO, XXVIII.7.4; 8.13; XXXII.22.10; XXXIV.59.1-2; BURTON, 2011, p. 206, n. 71.

${ }^{50}$ GENETTE, 1972 , p. 183-184.

${ }^{51}$ IX.42.8.

52 DAVIDSON, 1991; MCGING, 2010, p. 95-128; MILTSIOS, 2009; 2013; ZANGARA, 2007.

53 ZANGARA, 2007, p. 55-89.

${ }^{54} \mathrm{La}$ superposición de clementia y philanthropia, epieikeia y praótes: DE ROMILLY, 1979 , p. 235.

${ }^{55}$ La hipótesis de un posible choque cultural en este pasaje es mencionada por ERSKINE (2002, p. 97).

${ }^{56}$ DE ROMILLY, 1979 , p. 230.

57 WALBANK, 2006, p. 83; SCHUBART, 1936-1937. También entre póleis: GRAY, 2013, p. 152

${ }^{58}$ La baja época helenística y el alto imperio romano: MARTIN, 1961; HUNGER, 1963; LAFOND, 2006, p. 47-49. Para la relación con la guerra: PRÉAUX, 1961, p. 263-264, 285.

59 Philánthropos, philathénaios y philósophos: IsÓCrates, Cartas, V.2; MUCCIOLI, 2013, p. 365.

${ }^{60}$ Carta de Aristeas a Filócrates, 265.

${ }^{61}$ v.11.6. Cfr. virgiLio, 2007, p. 63.

62 Tiranía y realeza en Polibio: WeLWEI, 1963, p. 162-171.

63 walbank, 1999, HCP I, p. 549. Cfr. Platón, República, iII. 417 B; CiCERÓN, República, II.45; etc.

${ }^{64}$ ARISTÓTELeS, Política, III, 1286 b11; v, 1310 b35. Es esencial: LÉVY, 1996.

${ }^{65}$ Escipión "rey": X.40; beneficios a los jefes íberos (x.34.2-35.2; 37.7-38.3); euergetikòs (X.3.1; 5.6). Ver: GAUTHIER, 1985, p. 40-41. Domenico Musti pensaba que en Roma había una campaña contra Escipión y que el elogio excesivo podía tener como objetivo contrarrestarla: MUSTI, 1974, p. 135. Lo embarazoso del título real se adivina en las palabras que Livio coloca en boca de Escipión (regium nomen alibi magnum, Romae intolerabile esse: TITO LIVIO, XXVII.19.4), de todos modos, como apunta Frank WALBANK (1999, HCP II, p. 252), la referencia parece políticamente helenística.

${ }^{66}$ x.34.9; 38.3; xxi.4.3; xxxviII.20.11. "La clemencia de Roma, en Polibio es esencialmente la clemencia de Escipión el Africano": DE ROMILly, 1979, p. 240, 246. Sin embargo, es claro que existen diferencias entre la clementia romana y lo que Polibio decidió mostrar de la práctica de Escipión, por ejemplo, en el caso de Cartagena: PIANEZZOLA, 1969, p. 68-73.

${ }^{67}$ XVIII.37.7. Cfr. XXVII.8.8 (parà Romaiois éthos kaì pátrion esti). Anquises a Eneas: Virgilio, Eneida, VI.853.

${ }^{68}$ La býbris de los comandantes cartagineses y la consecuente pérdida de la eúnoia de sus aliados: ERSKINE, 2005, p. 229-235. Cfr. La perspectiva de DE ROMILLY (1979, p. 240), que pone el acento en el paralelo con la clementia, aunque reconoce que hay una lección de orden general pensada por Polibio.

${ }^{69}$ V.9-10.

70 aristóteles, Política, I.1255a; PLATÓN, República, V.468a; cfr. II.58.10. 
${ }^{71}$ DUCREY, 1982, p. 141.

72 PRitChetT, 1991, p. 245-312. Con un matiz más cínico: BIELMAN, 1994, p. $278-282$.

73 JENOFOnTE, Ciropedia, VII.5.73.

74 Jenofonte, Anábasis, V.6.32. Cfr. PAyen, 2012, p. 94.

75 II.57.8. Cfr. Plutarco, Arato, 36.3 (instalación de una guarnición e intervención en el ordenamiento político mantineo, al otorgar la ciudadanía a los metecos local).

${ }^{76}$ II.57.10.

77 plutarco, Arato, 45.6. Cfr. RostovtzefF, 1998, p. 194.

78 II.70.1. Sin embargo, uno de los vicios de Filipo II, según Teopompo, era tomar arteramente ciudades y reducir a esclavitud a sus habitantes (VIII.9.3; cfr. IX.28.3).

79 PAUL, 1982.

${ }^{80}$ Ix.39.2-3. Se repitió en 171 con Haliarto, cuando el pretor C. Lucrecio vendió a 2.500 de sus habitantes (TITO LIVIO, XLII.63.10-12). No se conserva el pasaje polibiano, pero hay ciertas evidencias de que debió hacer un comentario preciso al respecto: ECKSTEIN, 1995, p. 262, n. 86.

${ }^{81}$ PAUL, 1982, p. 146.

82 DUCREY, 1968, p. 75; KIECHLE, 1958, p. 149.

${ }^{83}$ Sobre la crítica a Filarco y la llamada historia “trágica”, ver: MARINCOLA, 2013.

${ }^{84}$ X.15-16; ERSKINE, 2000, p. 181.

${ }^{85}$ XVIII. 26.10.

${ }^{86}$ XX.9.11; MORENO LEONI, 2014.

${ }^{87}$ IX.42.8

${ }^{88}$ I.79.8.

${ }^{89}$ I.78.13-15.

${ }^{90}$ I.79.11; 80.2; 81.8.

91 TITO LIVIO, XXXII.22.10. Entre 207-206 a.C., aunque la datación presenta ciertas dificultades: BRISCOE, 1973, p. 209. Cfr. WALBANK, 1967 (1940), p. 98, n. 1 ; ERRINGTON, 1969 , p. 59, n. 1. Cfr. Con el trato despiadado a Cíos y sus consecuencias frente a la opinión pública griega (Xv.22-23).

92 DUCREY, 1968, p. 330-332.

93 TITO LIVIO, XXXII.22.9-10.

${ }^{94}$ DUCREY, 1968 , p. 338-339.

${ }^{95}$ Ibid., p. 339.

96 TARN Y GRIFFITH, 1969, p. 22-23.

${ }^{97}$ PRÉAUX, 1984, p. 104

${ }^{98}$ Entre 323/160 a.C. solo hubo seis años de paz entre las grandes monarquías: LÉVÊCQUE, 1968, p. 279. Cfr. Los reyes: AUSTIN, 1986. Las póleis: MA, 2000, p. 349-353; CHANIOTIS, 1996.

${ }^{99}$ ECKSTEIN, 2006, p. 79-117. La tesis de Harris (1985), de violencia excepcional romana, ha sido sostenida nuevamente (HARRIS, 2016, p. 66-67). Allí, el historiador británico llama la atención, de forma muy sugerente, sobre la desproporcionada ratio de participación social en el ejército, así como en la inusitada tasa de esclavización en masa de la guerra romana, incluso, en comparación con otros imperios como el de la China Qing o el británico moderno.

100 PAYEN, 2012, p. 94-95. Entre ellos: GLOTZ, 1923; KIECHLE, 1958; etc.

101 GRAINGER, 2000, p. 39.

102 PRITCHETT, 1991, p. 290-291. También las póleis griegas intercedían, como muestra el decreto en honor de Argos hallado en Palantio (Supplementum Epigraphicum Graecum 11: 1084, 11. 16-25); BIELMAN, 1994, p. 51. 
103 ECKSTEIN, 1989.

${ }^{104}$ v.10.4; XXII.16.2; cfr. DIODORO SíCulo, Biblioteca Histórica, XVI.87.1-3.

105 V.10.1; cfr. TUCÍDIDES, VIII.41.2; JENOFONTE, Helénicas, I.5.19; ESQUINES, Sobre la Embajada Fraudulenta, (II).16; DIODORO SícUlO, Biblioteca Histórica, XIX.85.3.

${ }^{106}$ Cfr. DEMÓsTenes, Sobre la Embajada Fraudulenta (XIX), 166; ESQUINES, Sobre la Embajada Fraudulenta, (II). 100; también: Démades, 9. La tradición de Teopompo tampoco es halagüeña con Filipo: TEOPOMPO, Fragmente der griechischen Historiker, 115 F 27.3 (=vIII.9.3). Cfr. Ix.28.3. Es interesante que Polibio, aun conociendo estas versiones, lo construyera como un ejemplo de philanthropia con los vencidos.

107 IX.28.4.

108 GRAY, 2013a, p. 337. Sobre la base de VI.6.4-7; II.61.

109 GUELFUCCI, 2010, p. 443. Prónoia y logismós "ambas confluyen para producir la anchinoia, 'inteligencia penetrante"': PÉDECH, 1964, p. 211.

${ }^{110}$ LEHMANN, 1989/90, p. 75-77. Incluso Filipo V ordena a sus hombres tratar con humanidad a Nicandro (autồ poiésasthai philánthropon), pero, antes de liberarlo, dice al etolio que "recordara en todo momento el beneficio recibido" (xx.11.6-8). Cf. TITO LIVIO, xxxVI.14.3-9; THORNTON, 2013, p. 156.

${ }^{111}$ XI.5.8.

112 XXII.8.9.

${ }^{113}$ Cfr. DMITRIEV, 2011, p. 146.

114 CHAMPION, 2000a, p. 428.

${ }^{115}$ IX.32.3-39.

${ }^{116}$ XI.4-6.8

117 XI.5.6.

118 CHAMPION, 2000a, p. 425, 433. Cfr. BRANDSTÄTER, 1844, p. 250; LA ROCHE, 1857, p. 68; MIONI, 1949, p. 115 , n. 4.

119 CHAMPION, 1997, p. 112-117.

120 CHAMPION, 2000, p. 1.

121 Sobre la naturaleza fundamentalmente didáctica: MAIER, 2012; GUELFUCCI, 2010.

122 XVIII.41.9. 